\title{
Caracterización del almidón de sagú (Canna indica) fermentado para la implementación de procesos agroindustriales
}

\author{
Characterization of fermented sago starch (Canna indica) for the \\ implementation of agro-industrial processes
}

\section{Caracterização do fermentado de amido de sagu (Canna indica) para \\ implantação de processos agroindustriais}

\author{
Chaparro Sánchez Sheila Solangie ${ }^{1}$, Romero López Wilmer Eliecer ${ }^{1}$ y \\ Rodríguez Rojas María Patricia ${ }^{2}$ \\ ${ }^{1}$ Ingenieras Agroindustriales, Universidad de los Llanos y \\ ${ }^{2}$ Ingeniera Química, PhD Ingeniería de Procesos y Ambiente \\ sheila.chaparro@unillanos.edu.co
}

Recibido 19 de agosto 2020 aprobado 16 de noviembre 2020

\section{RESUMEN}

El almidón de sagú (Canna indica) es de importancia para la agroindustria colombiana, sin embargo, la investigación sobre éste es poca, provocando que productos como el pan de sagú aún no se fabriquen de manera industrial. Estudios realizados con almidones de yuca demuestran que al fermentarse presentan mejores características frente a su estructura nativa para los procesos agroindustriales como la panificación. Por tal motivo se realizó el estudio del almidón fermentado de sagú para observar los cambios que genera la fermentación en su estructura frente al almidón nativo. Para el estudio se sometió el almidón a fermentación en tres relaciones diferentes de almidón-agua (1:2, 1:4 y 1:6) y se tomaron muestras del almidón a los días $5,10,15,20,25,30,35,40$ y 45 del proceso, a las cuales posteriormente se evaluaron propiedades fisicoquímicas, térmicas y microbiológicas. Se determinó que la relación entre los días de fermentación y las variables de acidez, humedad, densidad, cenizas y tamaño de partícula (menores a $125 \mu \mathrm{m}$ ) es directa (correlación de Pearson), es decir son directamente proporcionales. Contrario pasa con las variables $\mathrm{pH}$, temperatura de gelatinización y viscosidad máxima cuya relación es inversa, o negativa, es decir, 
disminuyen a medida que transcurren los días de fermentación. Estadísticamente se comprobó que la relación almidón-agua empleada en la fermentación del almidón de sagú no afecta las variables mencionadas. Por otra parte, los resultados obtenidos de viscosidad y gelatinización en los días 40 y 45 de las relaciones 1:4 y 1:6 son aptos para productos como mermeladas, gelatinas, mayonesas, dulces de leche y productos de panadería ya que resisten temperaturas hasta de $75.3^{\circ} \mathrm{C}$ y tienden a aumentar la viscosidad en la etapa de enfriamiento, además de contar con $\mathrm{pH}$ bajos lo que ayuda al inhibir el crecimiento bacteriano y valores altos de acidez que aporta el sabor característico del almidón de sagú. Se demostró la existencia de levaduras y bacterias amilolíticas durante la fermentación. Cabe resaltar que estos almidones no son aptos para todas las aplicaciones de panificación, para seleccionar el tipo de pan que se puede hacer con estos almidones hay que realizarles una prueba de expansión.

Palabras clave: Almidón, sagú, fermentación, Canna indica.

\section{ABSTRACT}

The sagu starch (Canna indica) performs importance for the Colombian agroindustry, nevertheless, the research on this one is small, and provoking that products like the bread of sagu still is not made in an industrial way. In addition, it's very well known that the starches in his native structure present low efficiency during the industrial processes. Studies made with fermented starches of tapioca demonstrates that those starches present better characteristics for the agroindustrial processes in opposition to his native structure. For such a motive the present study of the starch was performed fermenting sagu (Canna indica) to observe the changes that the process generates in the starch of this plant in opposition to the native starch. For the study the starch was mixed with water in three different proportions from starch-water (1:2, 1:4 and 1:6) and bring under fermentation for 45 days. Samples of the starch was taken each five days $(5,10,15,20,25,30,35,40$ and 45$)$ in order to evaluate physicochemical, thermal and microbiological properties. It was determined that the relationship between the days of fermentation and the variables of acidity, humidity, density, ash content and particle size (less than $125 \mu \mathrm{m}$ ) is direct 
(Pearson correlation), that is, they are directly proportional. In contrast, the variables $\mathrm{pH}$, gelatinization temperature and maximum viscosity have an inverse or negative relationship, that is, they decrease as the days of fermentation pass. Statistically it was verified that the relation starch: water used in the fermentation of the sago starch does not affect the mentioned variables. On the other hand, the results obtained from viscosity and gelatinization on days 40 and 45 of the 1:4 and 1:6 ratios are suitable for products such as jams, gelatins, mayonnaises, milk sweets and bakery products since they withstand temperatures up to $75.3^{\circ} \mathrm{C}$ and tend to increase the viscosity in the cooling stage, in addition to having low $\mathrm{pH}$ which helps to inhibit bacterial growth and high values of acidity that provides the characteristic taste of sagu starch. The existence of yeasts and amylolytic bacteria was demonstrated during fermentation. It should be noted that these starches are not suitable for all bakery applications, to select the type of bread that can be made with these starches an expansion test must be made.

Keywords: Starch, sagu, fermentation, Canna indica.

\section{RESUMO}

O amido de sagu (Canna indica) é importante para a agroindústria colombiana, porém, há poucas pesquisas sobre ele, fazendo com que produtos como o pão de sagu ainda não sejam fabricados de forma industrial. Estudos realizados com amidos de mandioca mostram que quando fermentados apresentam melhores características em relação à sua estrutura nativa para processos agroindustriais como a panificação. Por este motivo, o estudo do amido de sagu fermentado foi realizado para observar as mudanças geradas pela fermentação em sua estrutura em relação ao amido nativo. Para o estudo, o amido foi fermentado em três proporções diferentes de amido-água (1:2, $1: 4$ e 1:6) e as amostras de amido foram coletadas nos dias $5,10,15,20,25,30,35,40$ e 45 do processo, para o qual foram avaliadas as propriedades físico-químicas, térmicas e microbiológicas. Determinouse que a relação entre os dias de fermentação e as variáveis acidez, umidade, densidade, cinzas e granulometria (menor que $125 \mu \mathrm{m}$ ) é direta (correlação de Pearson), ou seja, são diretamente proporcionais. O contrário ocorre com as 
variáveis $\mathrm{pH}$, temperatura de gelatinização e viscosidade máxima cuja relação é inversa, ou negativa, ou seja, diminuem com o passar dos dias de fermentação. Estatisticamente constatou-se que a relação amido: água utilizada na fermentação do amido de sagu não afeta as variáveis mencionadas. Por outro lado, os resultados de viscosidade e gelatinização obtidos nos dias 40 e 45 das relações 1:4 e 1:6 são adequados para produtos como geleias, geleias, maionese, doces de leite e produtos de panificação, pois resistem a temperaturas de até $75.3^{\circ} \mathrm{C}$ e tendem a aumentar a viscosidade na etapa de resfriamento, além de possuir baixo $\mathrm{pH}$ que auxilia na inibição do crescimento bacteriano e altos valores de acidez que conferem o sabor característico do amido de sagu. A existência de leveduras e bactérias amilolíticas foi demonstrada durante a fermentação. Deve-se notar que esses amidos não são adequados para todas as aplicações de panificação.Para selecionar o tipo de pão que pode ser feito com esses amidos, um teste de expansão deve ser realizado.

Palavras-chave: Amido, sagu, fermentação, Canna indica.

\section{INTRODUCCIÓN}

En Colombia se pueden encontrar gran cantidad de productos de origen agrícola importantes para la industria como son los tubérculos y dentro de éstos el sagú, el cual es una fuente significativa de almidón usada en algunas regiones del país. Dentro de las plantas conocidas comúnmente como sagú se encuentran las especies Canna indica, Canna edulis, Maranta ruiziana y Maranta arundinacea. Actualmente el cultivo de achira o sagú y la extracción de sus almidones se encuentra concentrada en algunas regiones del país, siendo como principal la zona oriental de Cundinamarca, el sur de Huila y en algunos municipios de los departamentos de Nariño, Cauca, Meta y Tolima, donde su producción y venta (principalmente del almidón de sagú) representa una parte de la dieta alimentaria (panificados) además de ser la principal fuente de ingresos y de empleo (Rodríguez et al., 2003). 
En el país se presenta una demanda de dos mil toneladas al año de almidón de achira o sagú, de las cuales el $94.6 \%$ son producidas en Cundinamarca y el $5.4 \%$ en el Huila, siendo este uno de los principales consumidores, seguido por Tolima y Cundinamarca (Rodríguez et al., 2003). Su principal uso se encuentra en la agroindustria de panificación y microempresas artesanales cuyo principal uso es en la fabricación de los bizcochos de achira, que han constituido un símbolo regional y posicionado en los mercados locales y nacionales (Caicedo y Rozo, 2003). Económicamente la producción del almidón y pan de sagú se encadena con la producción artesanal, siendo este el principal uso del almidón en el mercado colombiano (Rodriguez y Garcia, 2003).

Aunque el almidón de sagú es de importancia para la agroindustria colombiana la investigación sobre éste es poca (o los resultados se encuentran reservados como secretos industriales), provocando que productos como el pan de sagú aún no se fabriquen de manera industrial, al contrario de la achira que ya tiene un mayor desarrollo de producto. Además, se ha determinado que los almidones en su estructura nativa presentan poca eficiencia durante los procesos industriales (Bello et al., 2002). Estudios realizados con almidones de yuca demuestran que al fermentarse presenta mejores características frente a su estructura nativa para los procesos agroindustriales, teniendo así un mejor aprovechamiento de este.

Debido a la falta de documentación respecto al análisis del almidón de sagú modificado por el método de fermentación (alteración de la estructura nativa de los almidones) (Alonso et al., 2016), se realiza este proyecto investigativo con el fin de conocer las propiedades del almidón de sagú modificado por esta vía y sus ventajas en el sector agroindustrial en especial en el sector de panificación, con el objetivo de otorgar a los productos elaborados a partir de éste almidón características diferentes a las que se manejan en el mercado.

El objetivo principal de este estudio fue evaluar el efecto de diferentes condiciones de fermentación en las propiedades fisicoquímicas del almidón de sagú (Canna indica). 


\section{METODOLOGÍA}

\section{Diseño experimental}

El análisis estadístico de los datos obtenidos durante la fermentación del almidón de sagú se ejecutó mediante un diseño de medidas repetitivas, con dos factores y diez niveles, a un nivel de significancia ( $\alpha$ ) de 0.05 . Este análisis se realizó por medio del programa estadístico Minitab 17 con los análisis de ANOVA anidada de dos factores y de Correlación de Pearson. Factor 1: tiempo de fermentación, y Factor 2: relación almidón-agua. Niveles: 10 niveles $(0,5,10,15,20,25$ 30, 35, 40 y 45 días de fermentación). Las variables de respuesta fueron: tamaño de partícula $(\mu \mathrm{m})$, densidad aparente, acidez, $\mathrm{pH}$, contenido de cenizas, porcentaje de humedad, tamaño de partícula por microscopía electrónica de barrido ambiental (SEM), perfil micro visco-amilográfico. Los análisis de ANOVA anidada de dos factores: hipótesis nula $(\mathrm{Ho})$ : si $\alpha<p$ entonces se acepta $\mathrm{Ho}$, hipótesis alternativa $(\mathrm{Ha})$ : si $\alpha>p$ se rechaza Ho y se acepta Ha y nivel de significancia: $\alpha=0.05$.

Ho1 = La propiedad estudiada del almidón no varía con los días de fermentación.

Ho2 = La propiedad estudiada del almidón no varía con la relación almidón-agua

Ha1 = La propiedad estudiada del almidón varía con los días de fermentación.

$\mathrm{Ha}_{2}=$ La propiedad estudiada del almidón varía con la relación almidón-agua

También se realizaron análisis de correlaciones de Pearson: Se realizó un análisis de Correlación de Pearson para conocer la relación que tiene los factores con las variables de respuesta. El coeficiente de correlación de Pearson varía entre cualquier valor comprendido entre $-1 y+1, r=1$, la correlación lineal es directa, $r=$ -1 , la correlación lineal es inversa y $r=0$, no existe correlación alguna, independencia de los valores $\mathrm{X}$ e $\mathrm{Y}$

\section{Proceso de obtención del almidón fermentado de sagú}

Fermentación: Se dejó el almidón lavado en tres recipientes a una relación 1:2, 1:4 y 1:6 respectivamente de agua y almidón de sagú durante 45 días para la 
fermentación espontánea. Se avaluaron las variables de respuesta cada cinco días, tomando muestras los días $0,5,10,15,20,25,30,35,40$ y 45 .

Secado del almidón: Después del lavado y fermentado se realizó la operación de secado al sol durante 5 horas con temperaturas que oscilaban entre los 28 y $38^{\circ} \mathrm{C}$ y un porcentaje de humedad entre 79 y $80 \%$,

Empaque y almacenamiento: Luego de secado, el almidón es recogido, desterronado y empacado en bolsas plásticas tipo ziploc para ser utilizado en los análisis posteriores.

Para los análisis posteriores del almidón de sagú se realizaron las pruebas del agua sobrenadante para la determinación del $\mathrm{pH}$, se realizó con los procedimientos de la AOAC 943.02 del 2005, se tomó como muestra el agua sobrenadante del tanque de fermentación, esto se realizó mediante un medidor de $\mathrm{pH}$ digital, el cual se calibra previamente con soluciones buffer de $\mathrm{pH}$ : 4.00, 7.00 y 10.00. Tomándose un volumen de $25 \mathrm{ml}$ del agua sobrenadante realizando la lectura de $\mathrm{pH}$. También se realizaron las pruebas de acidez titulable se realizó con en los laboratorios de la Universidad de los Llanos. Tomando $50 \mathrm{ml}$ del sobrenadante que fueron titulados con hidróxido de sodio $0.1 \mathrm{~N}$ utilizando fenolftaleína como indicador. La acidez se calcula a través de la ecuación número 1.

$$
\% \text { Acidez }=\frac{G \times N \times \text { mEq del ácido }}{g \text { muestra }} \times 100
$$

Donde:

G: Gasto de la solución de $\mathrm{NaOH}$

$N$ : Normalidad de la solución de $\mathrm{NaOH}$

$m E q$ del ácido: Miliequivalente del ácido predominante en la muestra

g muestra: Peso de la muestra analizar 


\section{Caracterización fisicoquímica}

Para la caracterización fisicoquímica del almidón fermentado de sagú se le realizaron, los siguientes análisis, siguiendo la metodología de Niño y Romero, (2016) y utilizando los procedimientos de laboratorio de la AOAC, (2005) y Aristizabal et al., (2007): pH, acidez titulable, cenizas densidad aparente, porcentaje de humedad, tamaño de la partícula $(\mu \mathrm{m})$ y perfil micro visco-amilográfico

Determinación del pH: Se tomó como muestra el agua sobrenadante del tanque de fermentación, realizándose la dedición mediante un medidor de pH digital, el cual se calibró previamente con soluciones buffer de $\mathrm{pH}: 4,00,7,00$ y 10,00. Se tomaron volúmenes de $25 \mathrm{ml}$ de almidón y se realizó la lectura de $\mathrm{pH}$. Este procedimiento se realizó por triplicado

Acidez titulable: Se realizó con muestras de almidón nativo y fermentado, estas pruebas se ejecutaron en los laboratorios de la Universidad de los Llanos. Se mezclaron 20.0 gramos de almidón en base seca con $100 \mathrm{ml}$ de agua destilada (previamente hervida para eliminar el $\mathrm{CO}_{2}$ ) durante 15 minutos. Posteriormente se filtra a través de papel filtro y se tomaron $50 \mathrm{ml}$ del filtrado para la titulación con hidróxido de sodio $0.1 \mathrm{~N}$ utilizando fenolftaleína como indicador. Se calcula con la ecuación 1.

Cenizas: Se procedió a pesar cada uno de los crisoles de porcelana debidamente lavados y secados, luego se pesa aproximadamente 1 gramo de la muestra de almidón. Posteriormente se llevan las muestras a secado en la mufla marca Memmert durante 6 horas a temperatura de $550^{\circ} \mathrm{C}$. Una vez terminado el tiempo se apaga la mufla y se dejan las muestras en el desecador por una hora, y finalmente se pesan cada una de las muestras calcinadas en el crisol. Los resultados se analizan por medio de la ecuación 2.

$$
\% \text { Cenizas }=\frac{\text { Peso de las cenizas }(g)}{\text { Pesa de la muestra }(g)} \times 100
$$

Densidad aparente: La densidad aparente del almidón se determinó siguiendo la metodología propuesta por Smith en 1967, en la cual se pesa una probeta graduada 
previamente lavada y secada, y posteriormente se adiciona la muestra del almidón hasta el volumen total, se registra el peso total. Este procedimiento se realiza por triplicado aplicando la ecuación 3:

$$
\text { Densidad Aparente }=\frac{(\text { Peso probeta+almidón suelto })(g)-\text { Peso probeta vacia }(g)}{250 \mathrm{ml}}
$$

Porcentaje de humedad: Se rotularon cada una de las cajas de Petri debidamente lavadas y secadas y se registra su peso, luego se pesaron aproximadamente 5 gramos de la muestra de almidón, posteriormente se llevaron a secado en el horno convencional durante 4 horas a una temperatura de $105^{\circ} \mathrm{C}$. Transcurrido el tiempo se retiraron y se colocaron al desecador durante 30 min y enseguida se registró su peso. El porcentaje se obtiene con la ecuación 4.

$$
\% \text { Humedad }=\frac{\text { Peso residuo final }(g)}{\text { Pesa inicial }(g)} \times 100
$$

Tamaño de partícula $(\mu \mathrm{m})$ : La distribución del tamaño del gránulo de almidón se determinó siguiendo la técnica ISI, 2015. Se pesaron 100 gramos de la muestra de almidón y se colocaron en la parte superior del arreglo de 5 tamices $(850,250,212$, 150 y $125 \mu \mathrm{m})$. Posteriormente se agitaron los tamices por aproximadamente 10 minutos. El Tamaño de partícula por microscopía electrónica de barrido ambiental (SEM) y la forma de los gránulos de almidón se evaluaron utilizando microscopía electrónica de barrido (SEM, con filamento de Tungsteno marca COXEM modelo EM 30AXPLUS) con una resolución de $5 \mathrm{~nm}$ en modo de alto vacío. El análisis se realizó utilizando condiciones de equipo de imágenes de aceleración de voltaje de $30 \mathrm{kV}$ en las superficies de fractura con la señal de retro dispersión de electrones. Imágenes con magnificación 20X hasta 150.000x (INTEK GROUP S.A.S, 2018).

Perfil micro visco-amilográfico: Para la realización de los ensayos de viscosidad se empleó un micro viscoamilógrafo POLTEC S.A., para lo cual el almidón se colocó en una suspensión de agua al $6 \%$, con base al peso seco según metodología 70 10. Elevando la temperatura inicial de $30^{\circ} \mathrm{C}$ hasta llegar a $95^{\circ} \mathrm{C}$ a una velocidad de $1.5^{\circ} \mathrm{C} / \mathrm{min}$; se mantuvo esta temperatura durante $15 \mathrm{~min}$. Por último, se descendió 
la temperatura hasta $50^{\circ} \mathrm{C}$ a una velocidad de $1.5^{\circ} \mathrm{C} / \mathrm{min}$. La viscosidad máxima se calculó a partir de los amilogramas resultantes (Martinez et al., 2015).

\section{Caracterización microbiológica}

Para la caracterización microbiológica del almidón fermentado de sagú se hicieron los siguientes procedimientos: aislamiento de bacterias, tinción de Gram, catalasa y amilasa.

Aislamiento de bacterias: Para el aislamiento se tomaron muestras del almidón en los días $0,5,10,15,20,25,30,35,40$ y 45 se sembraron por agotamiento en agar MRS para las bacterias acido lácticas y en agar almidón $1 \% \mathrm{p} / \mathrm{v}$, se sembró 0.1 $\mathrm{ml}$ del sobrenadante para la obtención de bacterias amilolíticas. Los agares se dejaron incubando a $37^{\circ} \mathrm{C}$ por 48 horas (Rincón y Villamil, 2005).

Tinción de Gram: Se tomó una muestra de las bacterias y se realizó un frotis en un portaobjetos, después se fijó la muestra y se adicionó Cristal violeta durante 1 minuto, luego se descartó el colorante adicionando agua, a continuación, se agregó Lugol y se permitió actuar por 1 minuto, se descartó y lavó con abundante agua. Posteriormente se adicionó alcohol acetona durante 20 segundos y se lavó. Finalmente se agregó el colorante fucsina durante 20 segundos, lavando la lámina y dejando secar. Después se adicionó una gota de aceite de inmersión y se observó en el microscopio a 100x (Benavides, 2007).

Prueba de catalasa: Se realizó tomando con un asa de inoculación del centro de una colonia, colocándola sobre un portaobjetos y agregándole una gota de peróxido de hidrógeno al 30\% sobre el cultivo y si se observa la inmediata liberación de gas, se toma como prueba positiva.

Prueba de amilasa: En el medio de cultivo de almidón, se realizó el recuento de UFC presentes, después se adicionó $1 \mathrm{ml}$ de Lugol y se dejó actuar, se deben observar las zonas de aclaramiento alrededor de las colonias y se realizó nuevamente el recuento para determinar las verdaderas colonias productoras de amilasa, después se realizó la medición del halo teniendo en cuenta la ecuación 5 . 


$$
C=A-B
$$

Donde:

A: diámetro de la colonia más el halo de hidrólisis en mm

$B$ : diámetro de la colonia en $\mathrm{mm}$

$C$ : Diámetro del halo de hidrólisis

\section{RESULTADOS Y DISCUSIÓN}

Los resultados obtenidos durante los 45 días de fermentación para la caracterización del almidón de sagú (Canna indica) fermentado para la implementación de procesos agroindustriales, en los cuales se evaluaron: Tamaño de partícula $(\mu \mathrm{m})$, densidad aparente, acidez, $\mathrm{pH}$, contenido de cenizas, porcentaje de humedad, tamaño de partícula por microscopia electrónica de barrido ambiental (SEM), perfil micro visco-amilográfico, se presentan a continuación.

\section{Caracterización fisicoquímica del almidón nativo y fermentado}

Determinación del pH. El comportamiento que presentó el pH durante los 45 días de fermentación, iniciando en un promedio de 6.27 para las tres relaciones almidónagua (1:2, 1:4 y 1:6), teniendo un descenso brusco entre los días 0 y 15, continuando con un comportamiento con pocas variaciones, volviéndose casi constante, hasta llegar a valores de $4.68 ; 4.83$ y 4.74 para las relaciones $1: 2$, $1: 4$ y $1: 6$ respectivamente en el día 45 de la fermentación. Este comportamiento fue similar en el $\mathrm{pH}$ del sobrenadante, iniciando con valores de $6.44 ; 6.86$ y 6.93 para las relaciones 1:2, 1:4 y 1:6 respectivamente, con un descenso brusco entre los días 5 y 10 y un comportamiento casi constante entre los días 20 y 45 , dando valores finales de 4.31, 4.26 y 4.13 para las relaciones $1: 2,1: 4$ y $1: 6$ respectivamente. indicándonos esto el efecto que tienen los microorganismos presentes sobre las cadenas de almidón, produciendo ácido láctico que provoca el descenso del pH.

El nivel de significancia de 0.05 es superior al $p=0.00$ respecto a los días de fermentación, rechazando con esto la hipótesis nula 1 y aceptando la hipótesis 
alternativa 1, que expresa que al transcurrir los días de fermentación varía el pH. Este descenso a medida que transcurre el tiempo lo confirma la correlación de Pearson que resulto negativa, es decir que es en sentido inverso. La significancia de 0.05 es menor al $p=0.973$ respecto a la relación almidón-agua, aceptando con esto la hipótesis nula 2 , que nos expresa que la relación almidón-agua no afecta la variación del $\mathrm{pH}$. Esto se atribuye a que el agua es un medio para disolver los componentes del almidón y que estos estén más disponibles para el consumo por parte de los microorganismos presente en la fermentación, por este motivo la relación almidón-agua no afecta a variación del pH.

Determinación de acidez titulable: Se puede observar un aumento de la acidez (calculado en términos de contenido de ácido láctico presente en el almidón) casi constante a partir del día 5 hasta el día 15, observando posteriormente un pequeño descenso en el día 20 y un aumento de la acidez para el día 25 en el que obtiene el punto más alto de acidez; y luego se observa un descenso de este parámetro -con unos picos de variaciones- hasta llegar al día 45 en el que aún mantiene valores levemente superiores a los iniciales.

Este ascenso de la acidez del almidón se le atribuye a las enzimas producidas por los microorganismos, ya que al aumentar los días de fermentación las enzimas producidas degradan la molécula de almidón, liberando glucosa susceptible a que se convierta en ácido láctico, aumentando la acidez (Miranda, 2014).

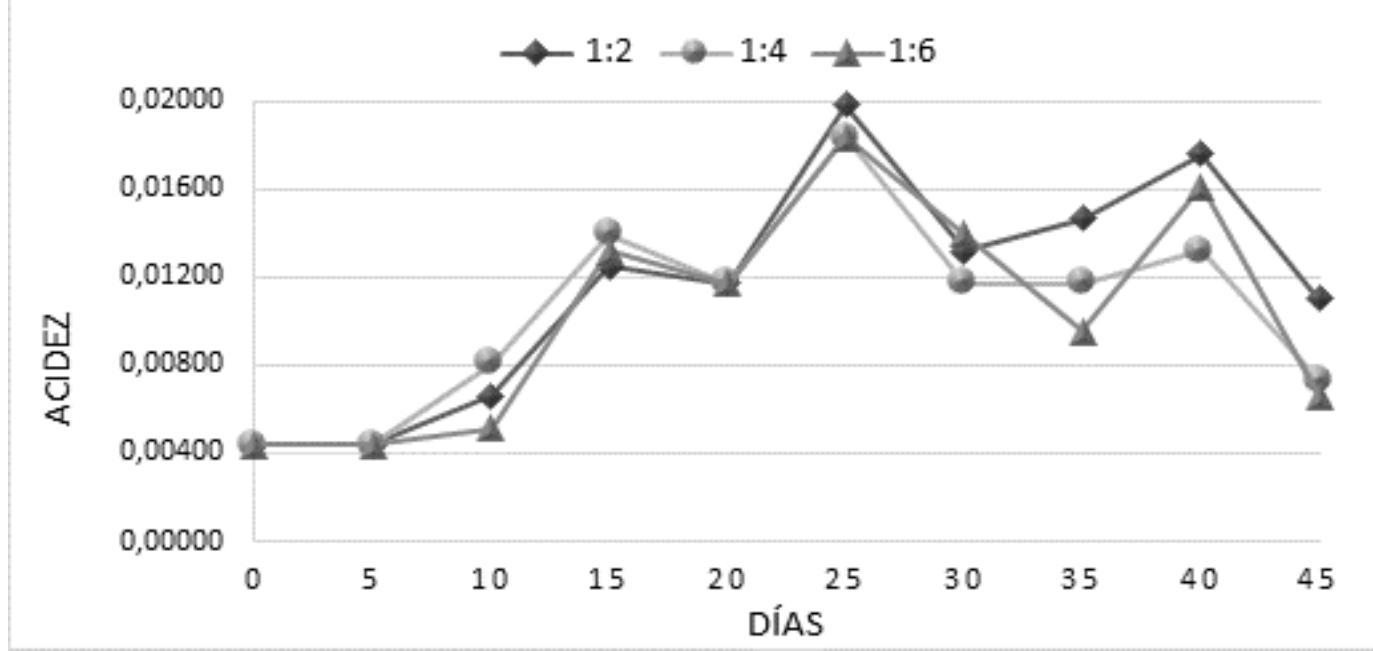

Gráfica 1. Comportamiento de la acidez durante la fermentación 
La significancia de 0.05 es superior al $p=0.00$ concerniente a los días de fermentación, rechazando con esto la hipótesis nula 1 y aceptando la hipótesis alternativa 1, que expresa que al transcurrir los días de fermentación varia significativamente la acidez. Esta acidez aumenta al transcurrir el tiempo, confirmándose a través de la correlación de Pearson que resultó positiva, es decir en sentido directo (Tabla 1).

Tabla 1. Correlación de Pearson positivas

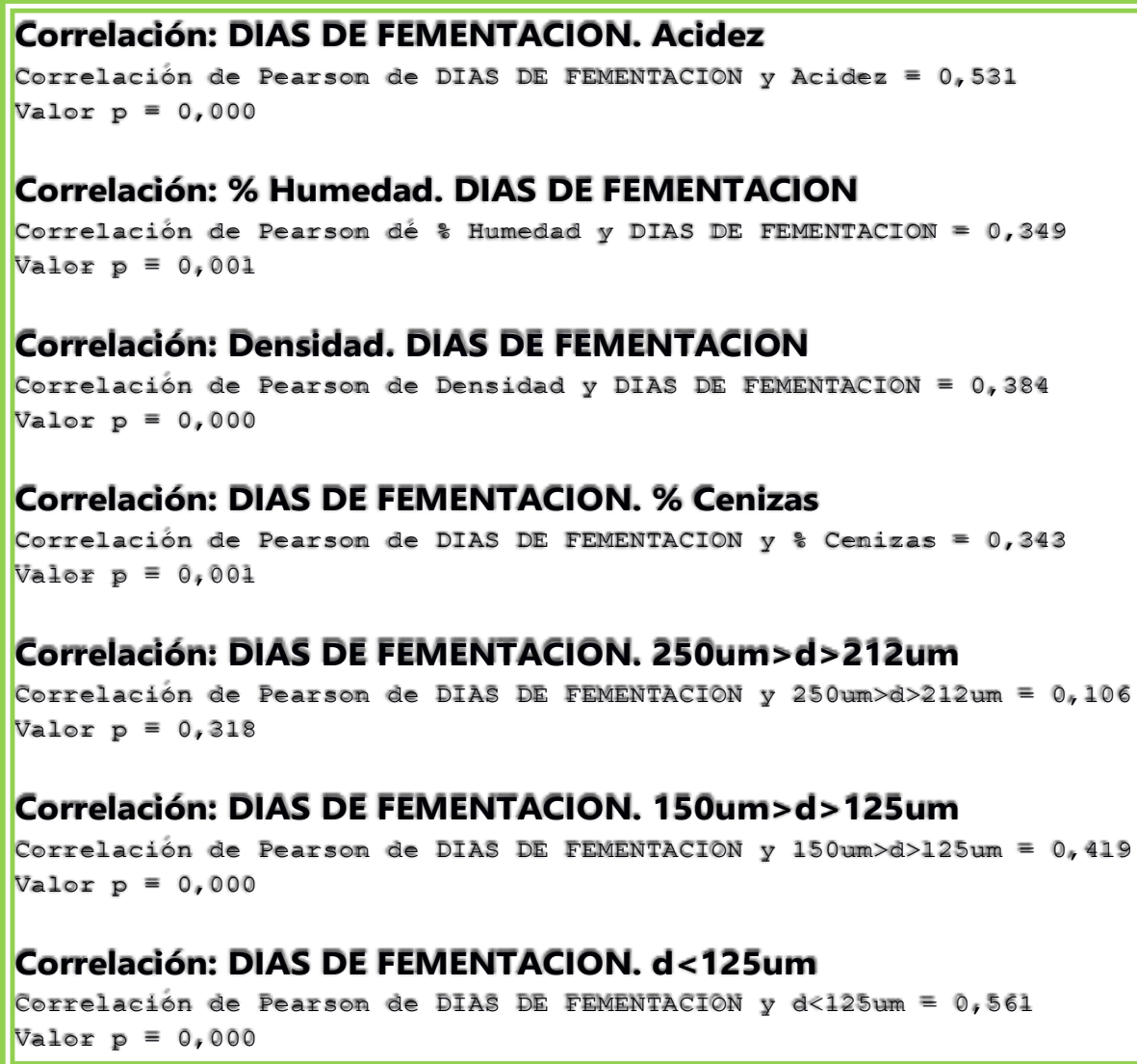

El nivel de significancia de 0.05 es menor al $p=0.826$ respecto a la relación almidónagua, aceptando con esto la hipótesis nula 2, que nos expresa que la relación almidón-agua no afecta la variación de la acidez. Esto se atribuye a que este líquido es un medio para disolver los componentes del almidón y que estos estén más disponibles para el consumo por parte de los microorganismos presente en la 
fermentación, que son los principales responsables de la variación de la acidez en el almidón, por este motivo la relación almidón-agua no afecta a variación de la acidez.

Contenido de cenizas: Se observa en el Gráfico 2 que el contenido de ceniza durante la fermentación, tenía valores iniciales de $0.1263 \mathrm{~g}$ en el día 0 , y finales de $0.1497 ; 0.1296$ y 0.1497 para las relaciones $1: 2,1: 4$ y $1: 6$ respectivamente en el día 45 , obteniendo un pico alto en el día 40 como se observa en la Gráfica 5, con valores de $0.1830,0.1863$ y 0.1963 para las relaciones $1: 2,1: 4$ y $1: 6$ respectivamente. No se observa una tendencia marcada al transcurrir la fermentación.

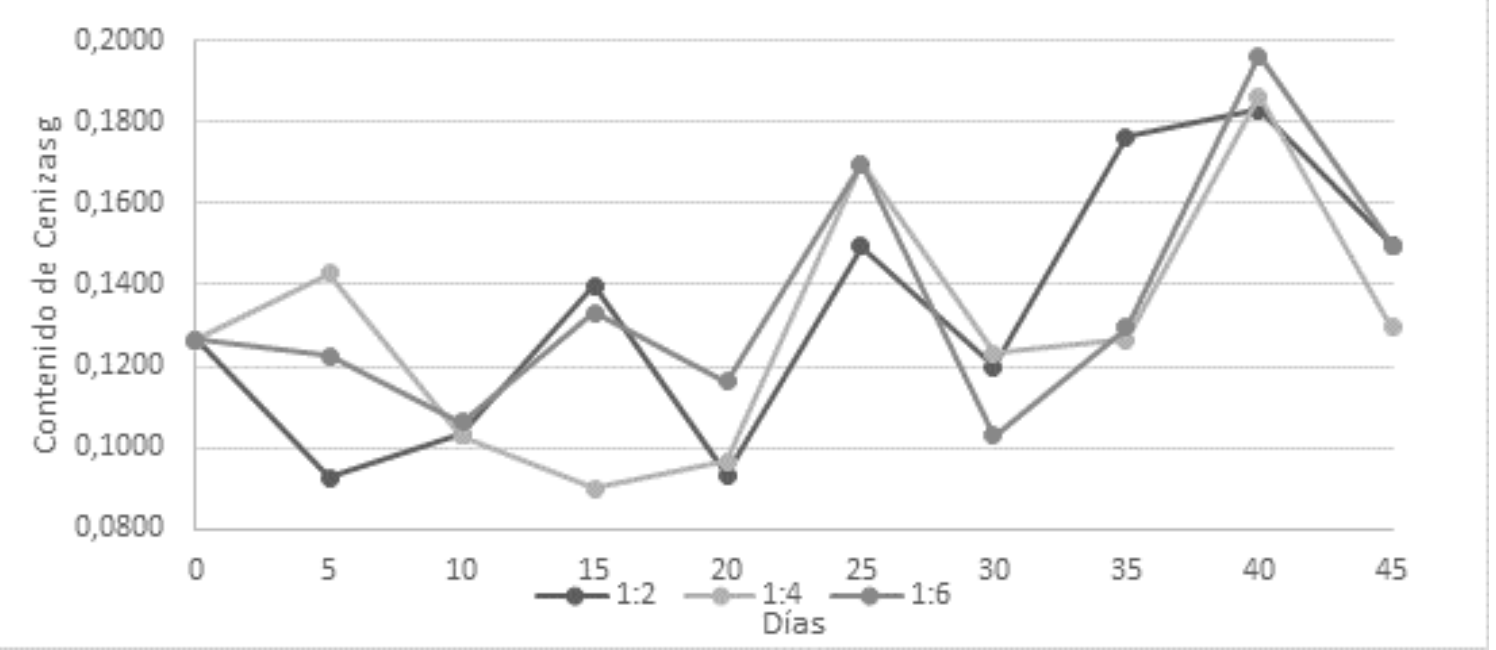

Gráfica 2. Comportamiento del contenido de ceniza durante la fermentación

Al comparar estos resultados con lo dicho por Aristizabal et al., (2007) para el almidón de yuca, estos superan el 0.12 por ciento de cenizas, por lo que se considera un almidón con alto contenido de cenizas. Sin embargo, los resultados obtenidos son influenciados por el proceso de secado, debido a que al estar expuestos al ambiente puede caer tierra, arena y/o polvo presente en el medio ambiente.

El nivel de significancia de 0.05 es superior al $p=0.046$ respecto a los días de fermentación, rechazando con esto la hipótesis nula 1 y aceptando la hipótesis alternativa 1, cuya expresa que al transcurrir los días de fermentación varía el \% de 
cenizas en el almidón. Este porcentaje aumenta a medida que trascurren los días, confirmando lo anterior la correlación de Pearson que resultó positiva, es decir en sentido directo (Tabla 1).

La significancia de 0.05 en inferior al $p=0.907$ respecto a la relación almidón-agua, aceptando con esto la hipótesis nula 2, que nos expresa la relación almidón-agua no afecta la variación del contenido de cenizas en el almidón. Esto se atribuye a que a pesar que las cenizas son solubles en el agua, esta no afecta la cantidad de cenizas presente en la muestra y son fácilmente recuperables por medio de una evaporación a altas temperaturas, por este motivo la relación almidón-agua no afecta a variación del pH.

Densidad aparente: se encontró que los valores obtenidos de la densidad del almidón durante la fermentación, van desde $0.66 \mathrm{~g} / \mathrm{ml}$ para al día cero, hasta valores de $0.75,0.75$ y $0.78 \mathrm{~g} / \mathrm{ml}$ para las relaciones $1: 2,1: 4$ y $1: 6$ respectivamente en el día 45, obteniendo su mayor densidad en el día 25 con valores de 0.82, 0.81 y 0.79 $\mathrm{g} / \mathrm{ml}$ para las relaciones 1:2, 1:4 y 1:6 respectivamente (Gráfica 3). Observando con esto que la densidad aparente del almidón de sagú se acerca a la densidad del agua, resultados similares fueron obtenidos por Granados et al., (2014).

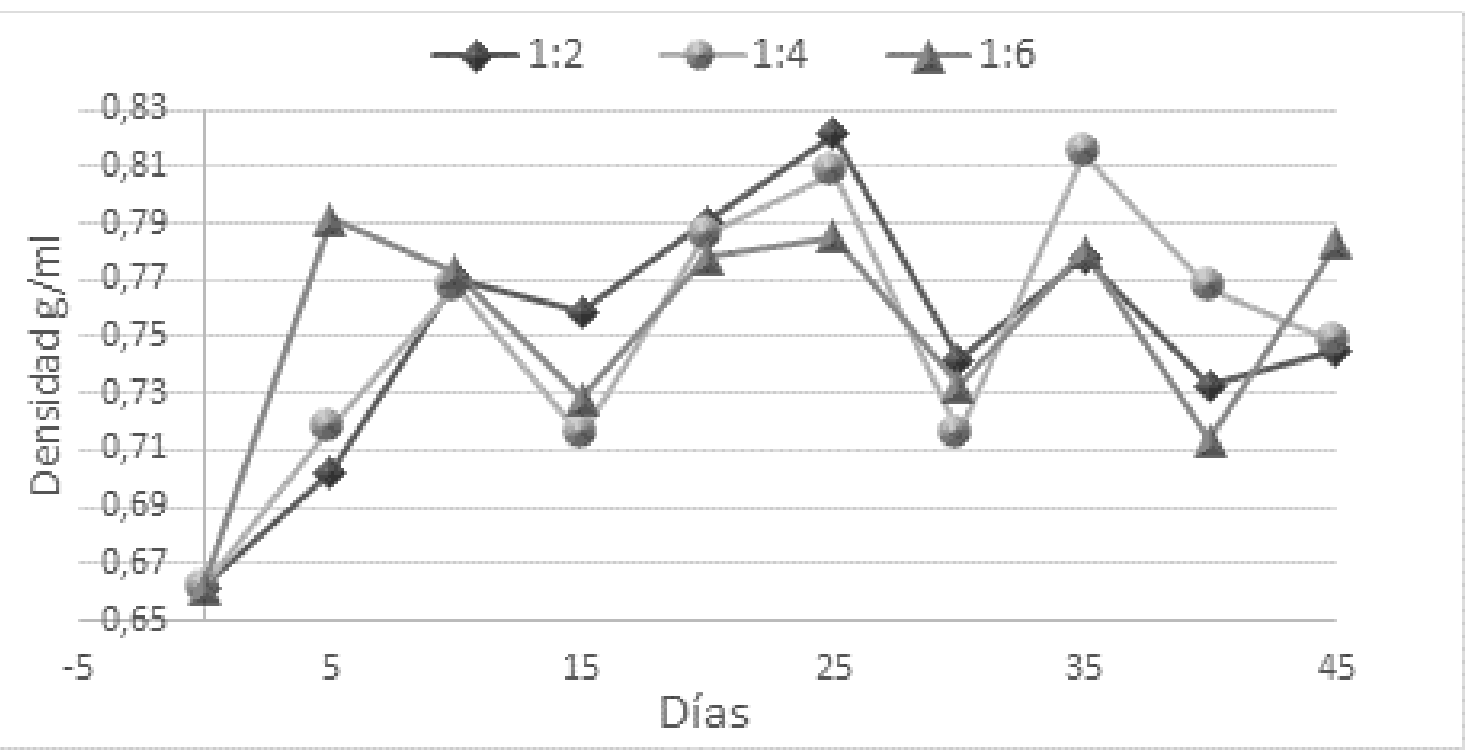

Gráfica 3. Comportamiento de la densidad durante la fermentación 
El nivel de significancia de 0.05 es superior al $p=000$ concerniente a los días de fermentación, rechazando con esto la hipótesis nula 1 y aceptando la hipótesis alternativa 1, que expresa que al transcurrir los días de fermentación varia la densidad aparente del almidón. Esta densidad aumenta al transcurrir el tiempo, confirmando esto la correlación de Pearson que resultó positiva, es decir en sentido directo (Tabla 1).

Por otro lado, el nivel de significancia de 0.05 es menor al $p=0.990$ respecto a la relación almidón-agua, aceptando con esto la hipótesis nula 2, que expresa que dicha relación no afecta la variación de la densidad del almidón. El agua al ser un medio para disolver los componentes del almidón y que estos estén más disponibles para el consumo por parte de los microorganismos presente en la fermentación, no ejerce gran influencia en la densidad del almidón, debido a que a temperatura ambiente los gránulos de almidón son insolubles en agua (Ovelar, 2019), absorbiendo pequeñas cantidades de esta, que no afecta la densidad del almidón.

Porcentaje de humedad: En la Gráfica 4 se observa el comportamiento de la humedad durante la fermentación, se obtuvieron mediciones por encima y por debajo del porcentaje de humedad inicial (15.33\%) sin encontrar patrón definido, obteniendo valores finales de 20, 14.67 y $18 \%$ para las relaciones 1:2, 1:4 y 1:6 respectivamente. Esta variación se le atribuye a las condiciones ambientales, debido a que se realizó un secado al ambiente durante 5 horas con temperaturas entre los 28 y $38^{\circ} \mathrm{C}$ y porcentaje de humedad relativa entre 79 y $80 \%$, en los meses de octubre y noviembre del 2018. Este tipo de secado se acogió debido a que es el utilizado por los campesinos de la región para realizar la deshidratación del almidón.

Estos valores se encuentran entre los aceptados por Aristizabal et al., (2007) que indica que el porcentaje de materia seca para el almidón de yuca esta entre un 87 y $90 \%$. Teniendo en cuenta que los valores de materia seca obtenidos fueron entre el 80 y 84.67 por ciento, se considera que la diferencia radica principalmente por el método de secado empleado, pues al no realizarse a condiciones controladas se ve influenciado por la humedad del ambiente. 


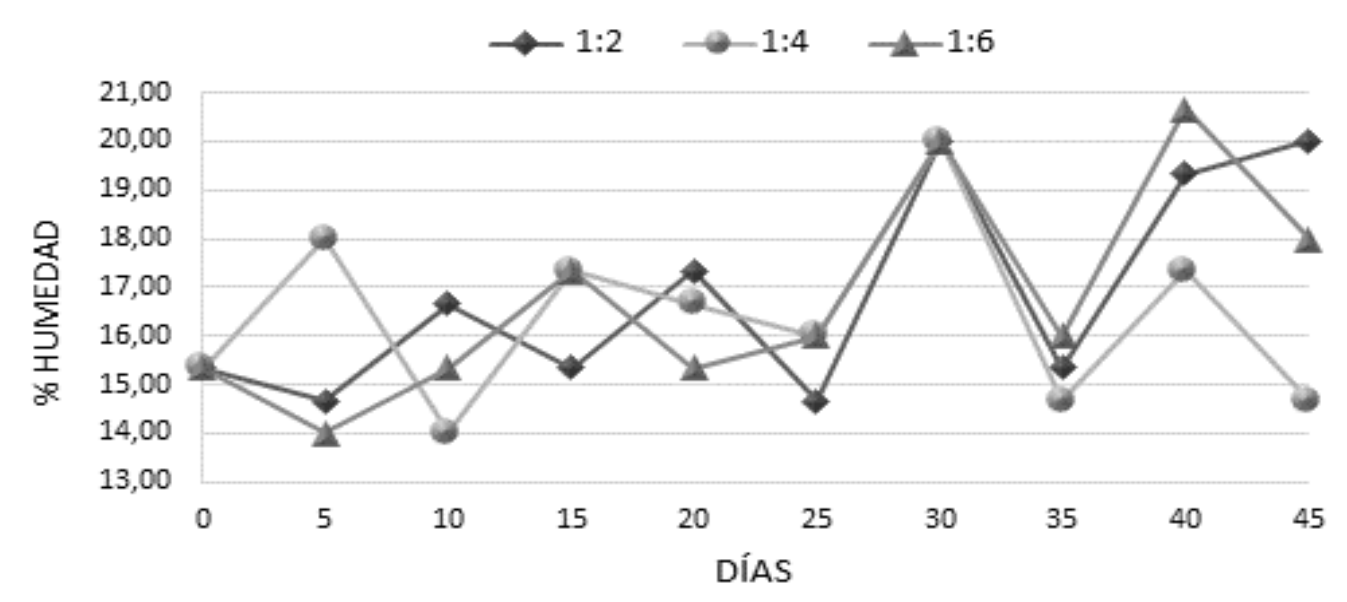

Gráfica 4. Comportamiento de la humedad durante la fermentación

La significancia de 0.05 es superior al $p=0.001$ respecto a los días de fermentación, rechazando con esto la hipótesis nula 1 y aceptando la hipótesis alternativa 1, que señala que al transcurrir los días de fermentación varía el porcentaje de humedad.

El porcentaje de humedad aumenta levemente al transcurrir el tiempo, confirmando esto la correlación de Pearson que resulto positiva, es decir en sentido directo (Tabla 1).

El nivel de significancia de 0.05 es menor al $p=0.862$ respecto a la relación almidónagua, aceptando con esto la hipótesis nula 2, que nos expresa la relación almidónagua no afecta la variación del porcentaje de humedad. El almidón al ser insoluble a temperatura ambiente, absorbe pequeñas cantidades de agua, siendo estas insignificantes en las variaciones del porcentaje de humedad (Ovelar, 2019).

Tamaño de partícula: como se observa en la Gráfica 5, el porcentaje de retención para la criba de $125 \mu \mathrm{m}$ (criba de menor tamaño) aumenta a medida que transcurre el tiempo de fermentación, indicándonos que el tamaño de partícula disminuye. Esta disminución del tamaño de partícula es conveniente en algunos procesos de panificación, debido a que favorece la hidratación durante el amasado, las partículas pueden absorber mucha agua por tener una mayor área superficial y mayor resistencia a procesos de altas temperaturas (Niño y Romero, 2016). En las tablas B 6, B 7 y B 8 del anexo $\mathrm{F}$ se observan los datos de tamaño de partícula para cada una de las relaciones almidón-agua y cada uno de los tamaños de cribas utilizados. 


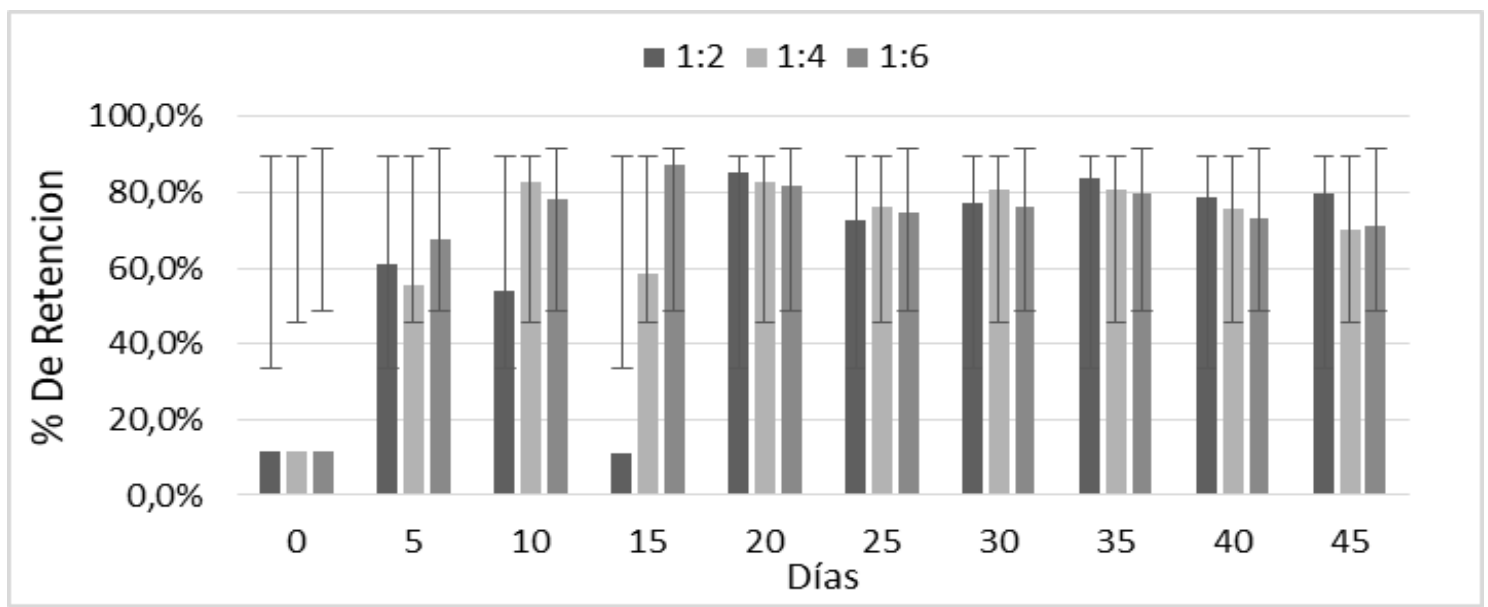

Gráfica 5. Comportamiento tamaño de partícula en la criba de $125 \mu \mathrm{m}$ durante la fermentación

El nivel de significancia de 0.05 es superior al $p=0.000$ concerniente a los días de fermentación, rechazando con esto la hipótesis nula 1 y aceptando la hipótesis alternativa 1, que señala que los días de fermentación afectan el tamaño de partícula en el almidón. El tamaño de partícula disminuye a medida que transcurren los días de fermentación, aumentando el porcentaje de retención en los tamices con menor calibre, confirmando lo anterior la correlación de Pearson que resultó positiva, es decir en sentido directo (Tabla 1).

Por otro lado, el nivel de significancia de 0.05 en inferior al $p=0.717$ respecto a la relación almidón-agua, aceptando con esto la hipótesis nula 2, que nos expresa que la relación almidón-agua no afecta el tamaño de partícula en el almidón. Esto es debido a que el agua no ejerce gran influencia en los gránulos de almidón -al ser insolubles a temperatura ambiente- por lo que no afecta el tamaño de partícula de este.

Tamaño de partícula por microscopia electrónica de barrido ambiental (SEM): en la Figura 1 se observan los gránulos de almidón de sagú, estos fueron gránulos redondeados y de forma ovalada con superficies lisas. Los gránulos (en el patrón base denominado como blanco, Figura 1J) tenían un tamaño de 34 a $60 \mu \mathrm{m}$, que se encuentra en los rangos reportado por Thitipraphunkul et al., (2003). 


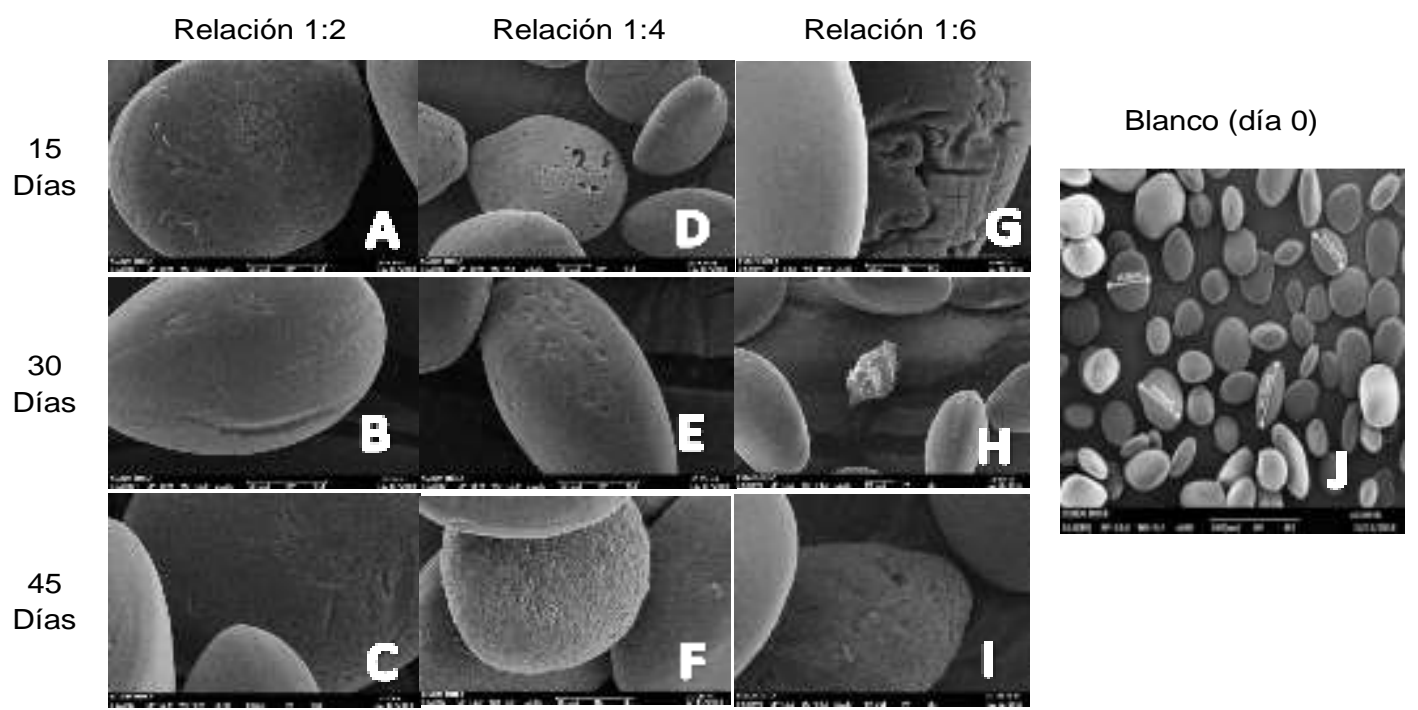

En la imagen (A) relación 1:2 día 15 aumento 5000x, (B) relación 1:2 día 30 aumento 5000x, (C) relación $1: 2$ día 45 aumento 5000x, (D) relación 1:4 día 15 a aumento 2000x, (E) relación 1:4 día 30 aumento 10000x, (F) relación 1:4 día 45 a aumento 10000x, (G) relación 1:6 día 15 aumento 5000x, (H) relación 1:6 día 30 aumento 10000x, (I) relación 1:6 día 45 aumento 5000x y (J) Blanco día 0 y $500 x$.

Figura 1. Imágenes de partículas de almidón de sagú obtenidas por microscopía electrónica de barrido (SEM).

Por otra parte se observa que, durante la fermentación los gránulos de almidón empezaron a ser degradados por las enzimas (Galvis, 2009) producidas por los microorganismos presentes y causantes de la fermentación (Velíz, 1984), este deterioro o consumo del gránulo del almidón se incrementa a medida que transcurre el tiempo de fermentación, observándose gránulos con superficies porosas y algunos con agujeros profundos, como se ve las imágenes D, G, F e I de la Figura 1. También se observa que el tamaño del gránulo del almidón no fue afectado por los días de fermentación, este mantuvo su rango entre 34 a $60 \mu \mathrm{m}$ desde el inicio hasta finalizar la fermentación.

\section{Perfil micro visco-amilográfico del almidón:}

Viscosidad máxima: Como se observa en la Gráfica 6, la viscosidad máxima del almidón aumenta a medida que trascurre el tiempo de fermentación, dándonos a conocer que su punto más alto de viscosidad máxima se encuentra en el día 10 de 
la fermentación con valores de 368, 390 y 369 BU para las relaciones 1:2, 1:4 y 1:6 respectivamente. También podemos observar que al pasar el décimo día de fermentación la viscosidad tiende a bajar y presentar unos valores casi constantes entre los días 40 y 45; teniendo valores finales de 302, 289 y 262 BU (Unidades Brabender) para las relaciones 1:2, 1:4 y 1:6 respectivamente.

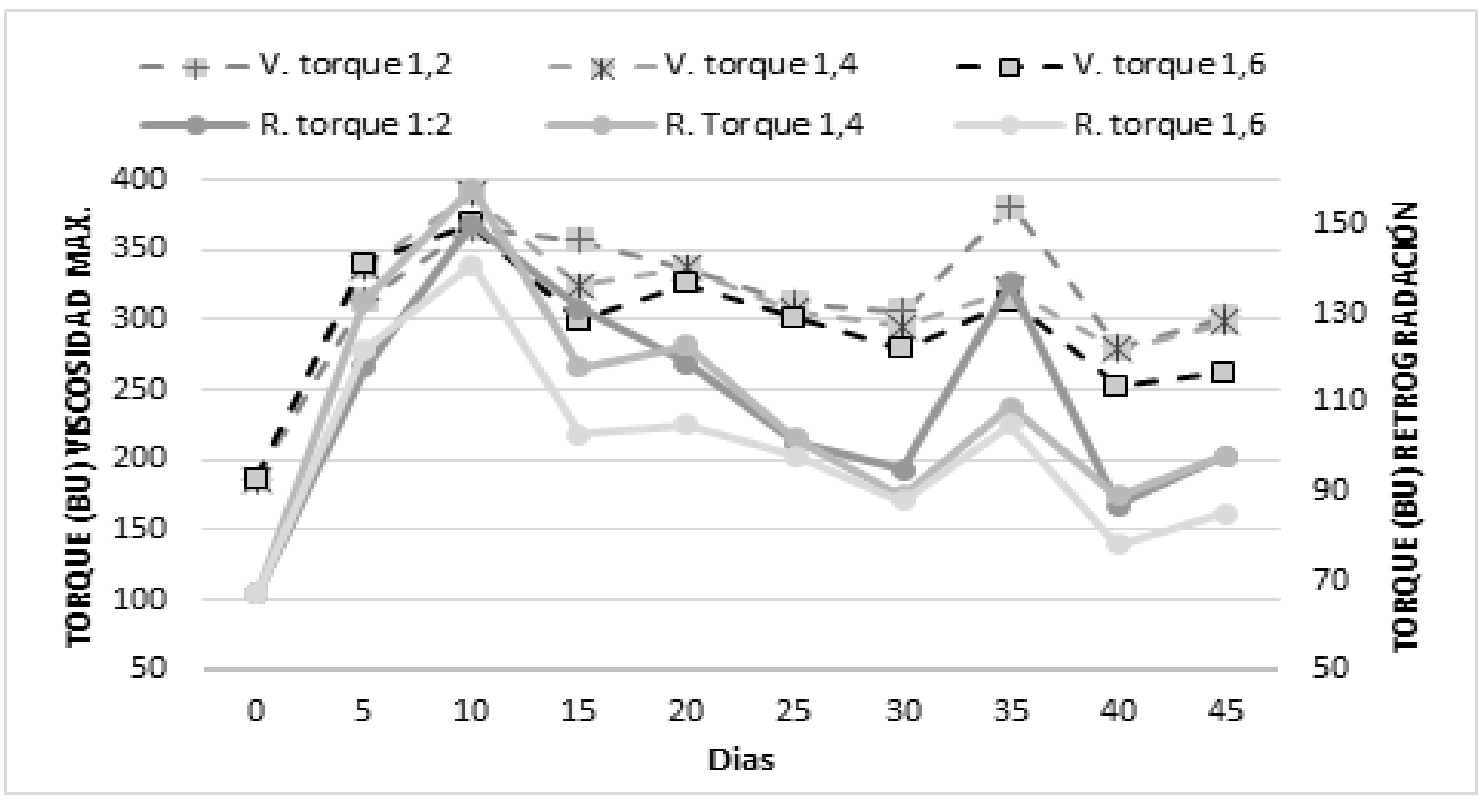

V: Viscosidad máxima, R: Retrogradación

Gráfica 6. Comportamiento de la viscosidad máxima durante la fermentación

En el día 10 se alcanza también el máximo valor de las muestras para la retrogradación (Setback) con valores de 150, 158 y 141 BU para las relaciones 1:2, 1:4 y 1:6 respectivamente, indicando que en este punto el almidón es menos susceptible a la degradación y más estable a los cambios de temperatura, sugiriendo una alta estabilidad de sus pastas a los esfuerzos mecánicos (Hernandez et al., 2008), pero como consecuencia tiene menor capacidad de ligar agua, por lo que el producto de panadería tiende a endurecerse más rápido. En comparación con los resultados obtenidos del blanco (viscosidad máxima 186 BU y Setback 67 $\mathrm{BU})$ este es menos estable a cambios de temperatura, por lo que tiende a cambiar ligeramente la viscosidad al momento del enfriado, pero tiene mayor capacidad de retención de agua, por lo que se obtiene una masa (en panadería) más fluida. La 
correlación de Pearson da un valor negativo - 0,276 , indicándonos que la viscosidad máxima disminuye a medida que trascurre el tiempo de fermentación.

Gelatinización: En las Gráficas 7, 8 y 9 se observa el comportamiento que tiene la temperatura de gelatinización durante los 45 días de fermentación. El almidón con relación 1:2 obtuvo unos picos bajos de temperatura de gelatinización en los días $10,15,35$ y 45 que vario entre 31.4 a $29.5^{\circ} \mathrm{C}$; igualmente se vio este comportamiento en el almidón con relación 1:4 en los días 10, 30 y 35 con valores entre 30.1 a $28.7^{\circ} \mathrm{C}$. En comparación a los dos anteriores el almidón con relación 1:6 tuvo un comportamiento más estable en la temperatura de gelatinización, tenido solo un descenso de esta en el día 30 con un valor de $29.1^{\circ} \mathrm{C}$. Estos tipos de almidones son perfectos para productos que necesitan formación de geles sin la necesidad de someterse a tratamientos con temperaturas altas (Mejia, 2019).

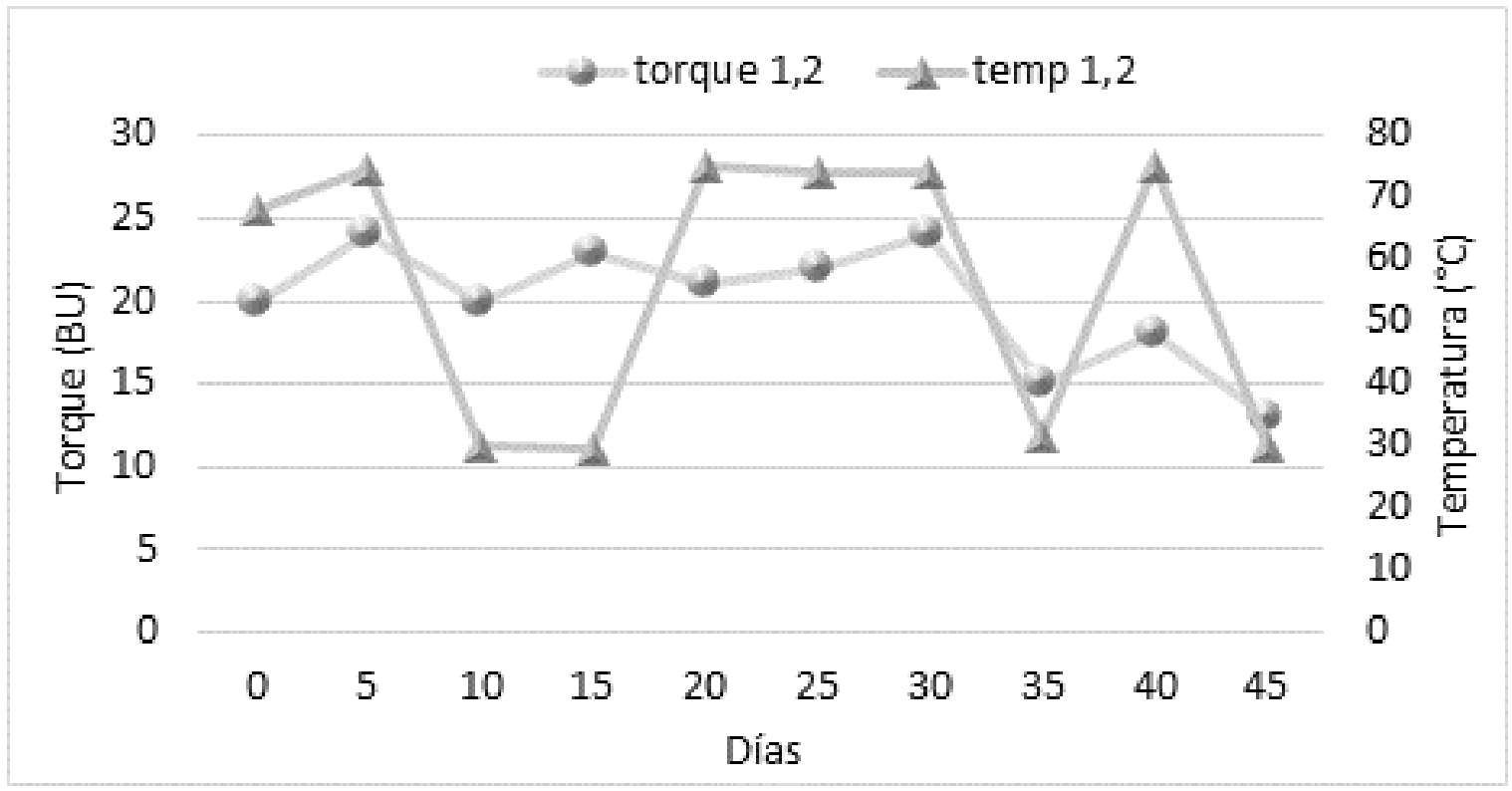

Gráfica 7. Comportamiento de gelatinización de la relación 1:2 durante la fermentación

En las tres relaciones se encontró que en el día 40 las muestras obtuvieron una temperatura de gelatinización superior a los $75^{\circ} \mathrm{C}$ muy similar a la reportada por Hernández et al., (2008) de 74.9 para el sagú y 784 para almidón del tubérculo de makal (Xanthosoma yucatanensis). 
Con relación a la correlación de Pearson esta es negativa -0.073 , muy cercana a cero, dándonos a entender que a medida que transcurren los días de fermentación tiende a presentar un pequeño descenso la temperatura de gelatinización.

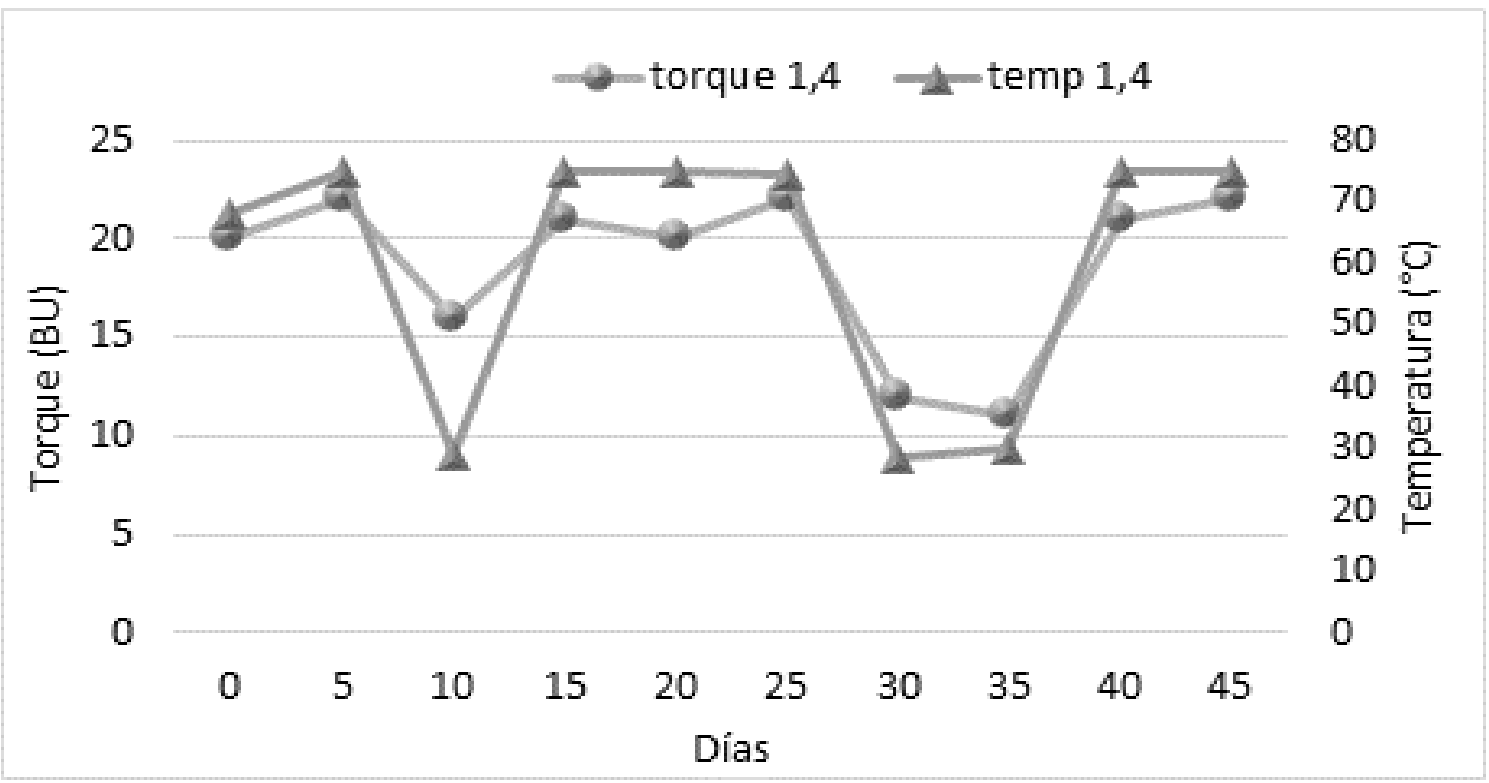

Gráfica 8. Comportamiento gelatinización de la relación 1:4 durante la fermentación

\section{Características microbiológicas de la fermentación del almidón}

La estructura básica de los sustratos sólidos está conformada por macromoléculas. Estas son la fuente de carbono, nitrógeno y energía para el desarrollo microbiano. La utilización de las macromoléculas requiere la síntesis y secreción de enzimas hidrolíticas por parte del microorganismo (Terebiznik, 1998), en la fermentación de almidones se ha encontrado que los principales microorganismos presentes son productores de enzimas amilasas (Canales y Chavez, 2014). Durante esta fermentación del almidón de sagú (Canna indica) se comprobó que sí había presencia de microorganismos amilolíticos y algunas levaduras, como se muestra en las Figuras 2 y 3 . Estos microorganismos amilolíticos encontrados se caracterizan por ser Gram negativos, con un halo de inhibición de $2 \mathrm{~mm}$, y catalasa positivos. Además, se observó que a medida que transcurría la fermentación, la presencia de estos microrganismos disminuía, esto fue atribuido al aumento de acidez en el medio (Ascheri, 2009). 


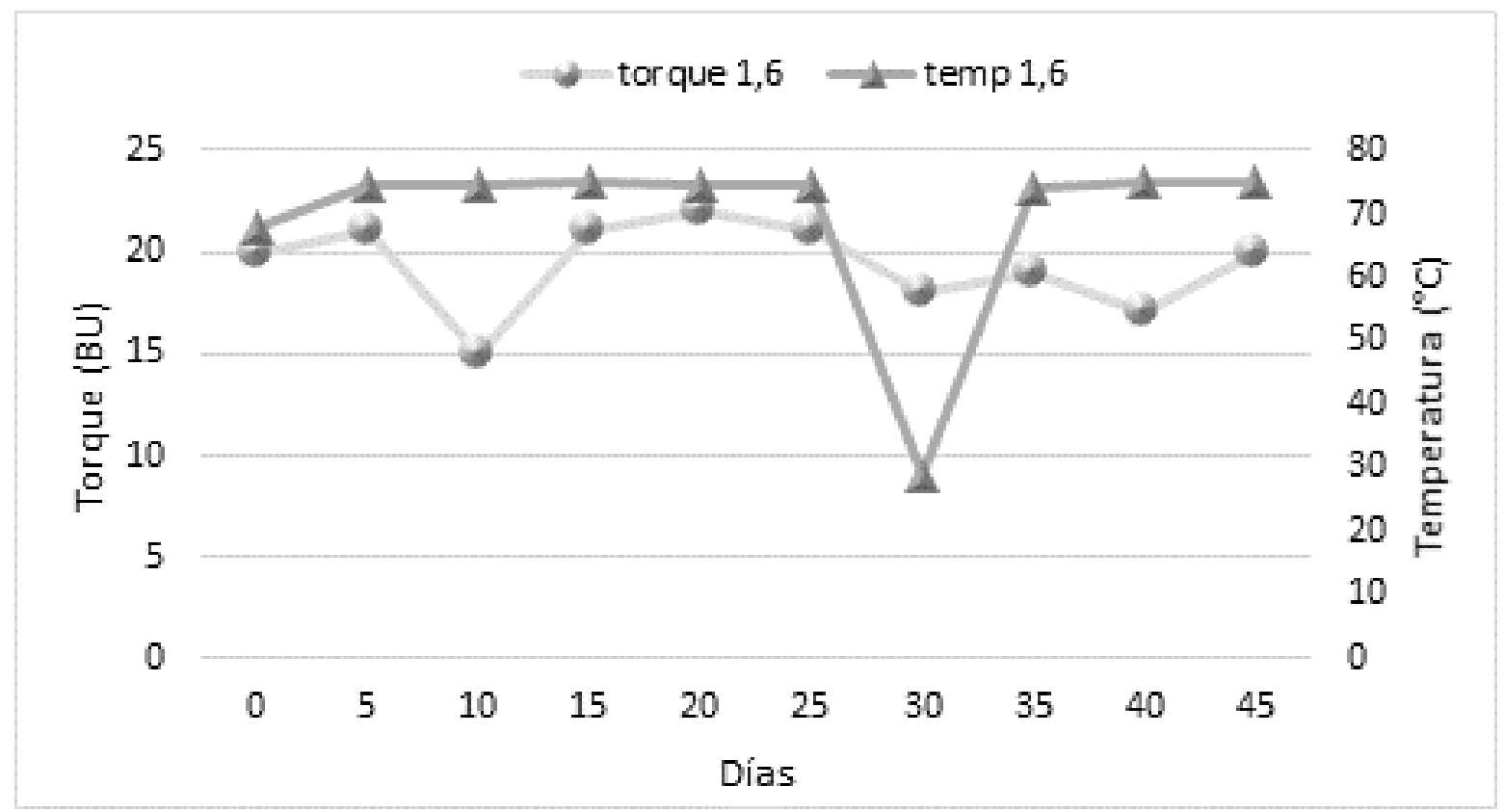

Gráfica 9. Comportamiento gelatinización de la relación 1:6 durante la fermentación

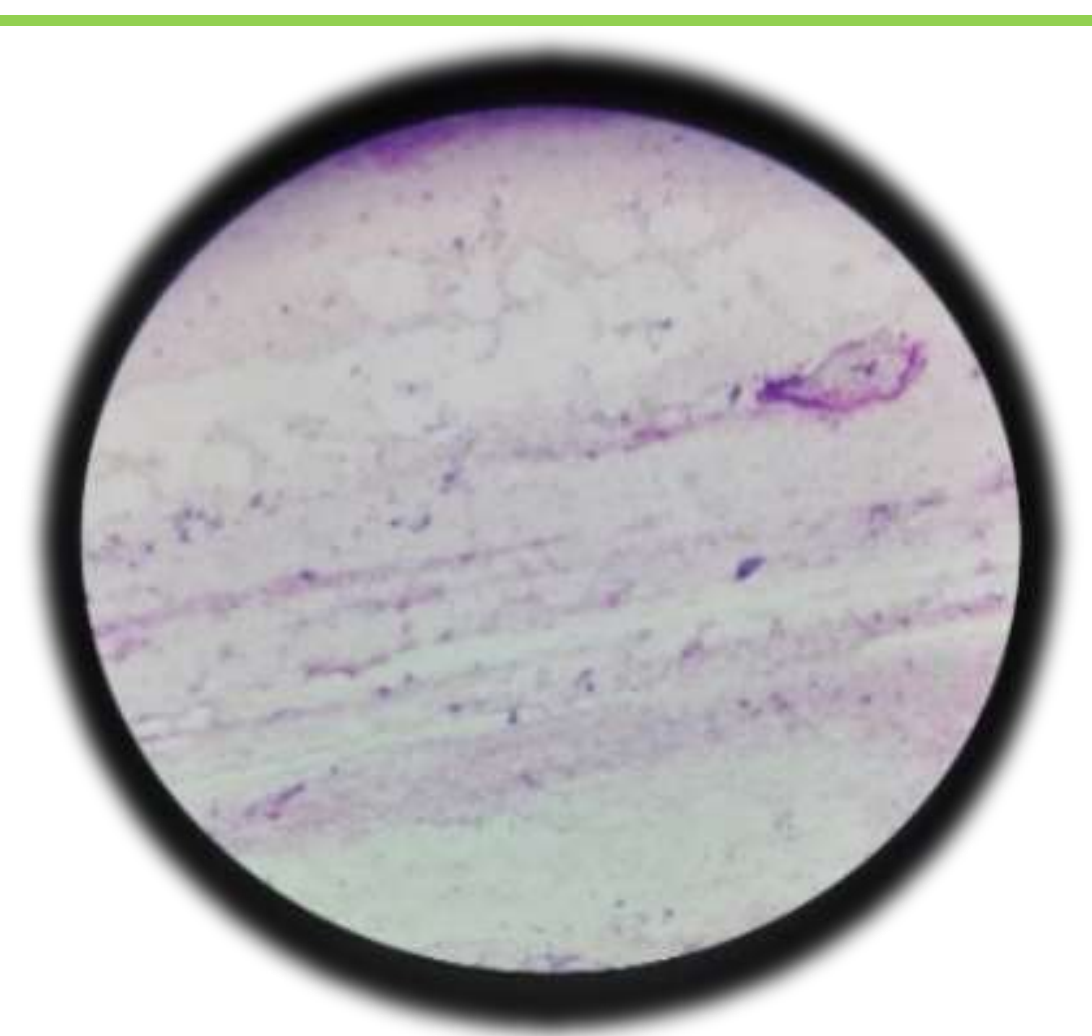

Figura 2. Crecimiento de bacterias amilolíticas Gram negativas. 


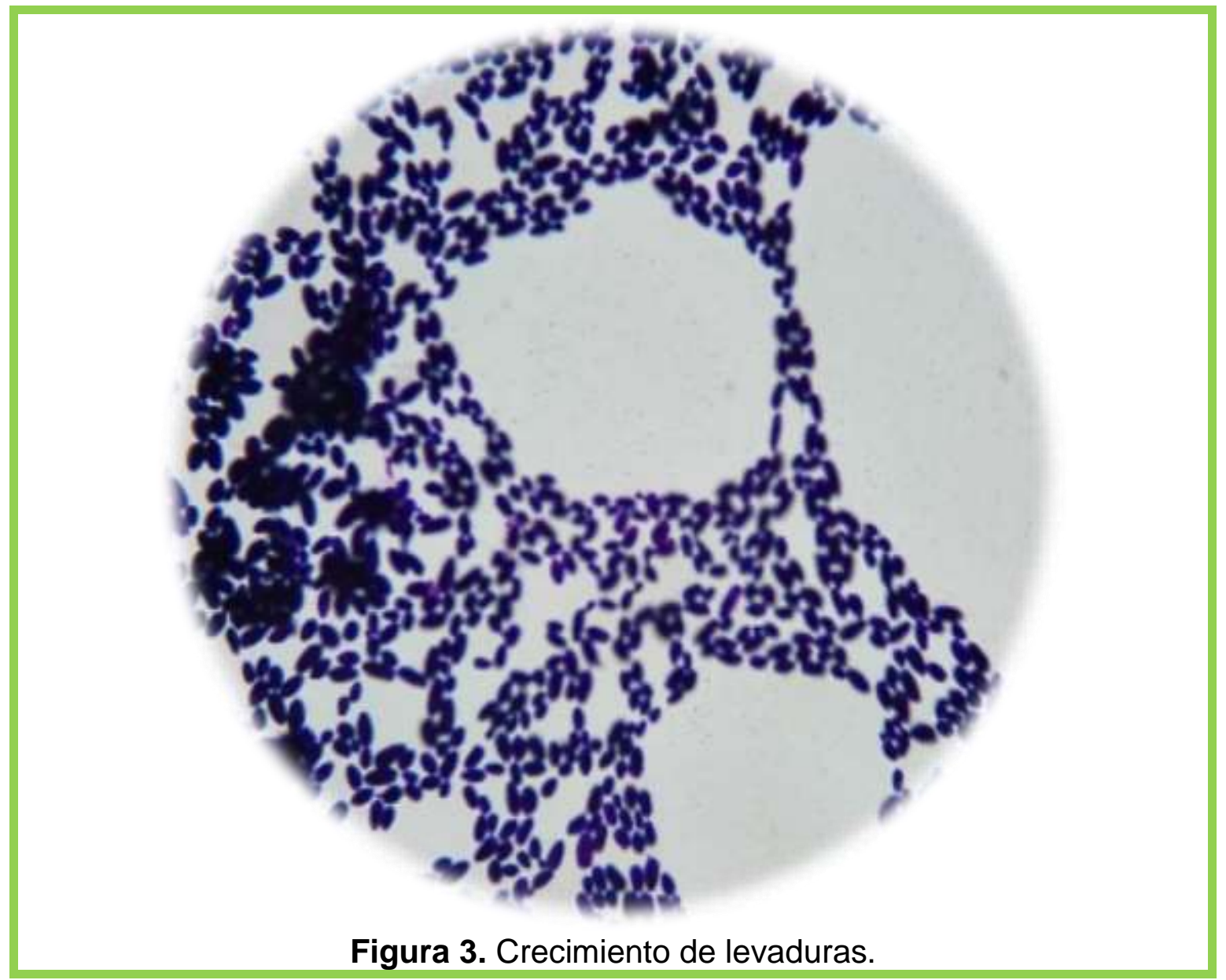

\section{CONCLUSIONES}

Se determinó que el tiempo de fermentación del almidón de sagú es fundamental para la elaboración de almidón agrio de sagú, dependiendo de los días de fermentación el almidón nos aporta características especiales para diferentes tipos de productos y procesos de producción.

Los almidones con temperaturas de gelatinización inferiores a $40^{\circ} \mathrm{C}$ como los encontrados en la relación 1:2 en los días 10,15, 35 y 45, y en la relación 1:4 en los días 10,30 y 35 al tener una temperatura de gelatinización baja y una alta resistencia a la deformación por esfuerzo mecánico, provocando que sean geles estables a temperatura ambiente son aptos para productos de confitería como gomas o geles con baja fluidez. Para fabricar productos que necesiten una alta 
fluidez se recomienda la utilización del almidón a 40 días de fermentación de la relación 1:6.

Por otra parte, los resultados obtenidos de viscosidad y gelatinización en los días 40 y 45 de las relaciones $1: 4$ y 1:6 son aptos para productos como mermeladas, gelatinas, mayonesas, dulces de leche y productos de panadería ya que resisten temperaturas hasta de $75.3^{\circ} \mathrm{C}$ y tienden a aumentar la viscosidad en la etapa de enfriamiento, además de contar con pH bajos lo que ayuda al inhibir el crecimiento bacteriano y valores altos de acidez que aporta el sabor característico del almidón de sagú. Cabe resaltar que estos almidones no son aptos para todas las variedades de panes, para seleccionar el tipo de pan que se puede hacer con estos almidones hay que realizarles una prueba de expansión.

La relación que tiene los días de fermentación con las variables de acidez, humedad, densidad, cenizas y tamaño de partícula (menores a $125 \mu \mathrm{m}$ ) muestra una relación directa, confirmándolo la correlación de Pearson; a mayor tiempo de fermentación afecta de manera positiva las variables. Contrario pasa con las variables $\mathrm{pH}$, temperatura de gelatinización y viscosidad máxima cuya relación es inversa, es decir, negativa, disminuyen a medida que transcurren los días de fermentación.

Estadísticamente se comprobó que la relación almidón-agua empleada en la fermentación del almidón de sagú no afecta las variables de $\mathrm{pH}$, acidez, humedad, densidad aparente, contenido de cenizas y tamaño de partícula.

\section{RECOMENDACIONES}

Esta investigación se realizó con las condiciones en las que se procesa actualmente el almidón de sagú en la región, por lo que se recomienda a las personas que deseen continuar con investigaciones similares realizar un secado en condiciones controladas o secado artificial, ya que este punto es crítico para la obtención del producto final, debido a que los rayos UV -sin controlarlos- oxida excesivamente el almidón y al estar expuesto al ambiente puede aumentar el contenido de cenizas. 
A partir de los potenciales usos encontrados durante esta modificación de almidón de sagú (Canna indica), se recomienda que se realicen más estudios que permitan profundizar la caracterización de este almidón, principalmente pruebas como: expansión para el uso en panadería, pureza del almidón, contenido de amilosa y amilopectina, calorimetría diferencial de barrido, entre otras. Esto con el fin de complementar esta investigación y ser pioneros en la posible agroindustria de la fermentación de almidón de sagú.

Además, desde la perspectiva microbiológica se recomienda también realizar el sistema de fermentación a menor escala y de esta forma poder caracterizar los microrganismos presentes en la fermentación.

\section{REFERENCIAS BIBLIOGRÁFICAS}

1. Acevedo, A., Angarita, A., Leon, M. V., Franco, K. L. Sustentabilidad y variabilidad climática: acciones agroecológicas participativas de adaptación y resiliencia socioecológica en la región alto-andina Colombiana. Luna Azul, p 626. 2017.

2. Acosta A. P., Blanco C. Obtención y caracterización de almidones nativos colombianos para su evaluación como posibles alternativas en la industria alimentaria. Cartagena de Indias D.T.: Universidad de Cartagena. 2013.

3. Acosta A. A. Estudio de viscosidad aparente en sistemas simples y multifásicos de baja densidad en función de la temperatura, mediante el uso de viscoanalizador. s.I.: Universidad Autónoma de Querétaro. 2013.

4. Alonso L. et al. Physicochemical transformation of cassava starch during fermentation for production of sour cassava starch in Colombia. Starch, biosynthesis Nutrition Biochemical. 2016

5. Andrade, M., Tapia B, D., Menegalle, F. Physical-chemical, terminal and functional properties of achira (Canna indica L.) flour and starch from different geographical origin. Starch/Stärke, p 348-358. 2012.

6. Aristizabal, J., Sanchez, T., Mejia, D. Guía Técnica para la producción y análisis de almidón de yuca. En: Roma: Boletín de servicios agrícolas de la FAO, p 6191. 2007.

7. Ascheri D. Determinación del tiempo óptimo de la fermentación del almidón de yuca (Manihot Esculenta, Crantz), en la fabricación del almidón agrio. 2009. Disponible En: https://www.worldcat.org/title/determinacion-del-tiempo-optimode-la-fermentacion-del-almidon-de-yuca-manihot-esculenta-crantz-en-lafabricacion-del-almidon-agrio/oclc/780258090?referer=di\&ht=edition

8. Association Of Official Analytical Chemists International (AOAC). Ash of flour, ceniza de harina. $7^{\text {th }}$ ed. S.l.:s.n. 2000.

9. Association Of Official Analytical Chemists International (AOAC). pH de harina. s.l.:s.n. 2005. 
10. Association Of Official Analytical Chemists International (AOAC). 925.10/95. Official Methods of Analysis or Association of Afficial Analytical Chemists International. $17^{\text {th }}$ ed. s.l.:s.n., s.f.

11. Badui D, S. Hidratos de carbono. En: Química de alimentos. s.I.: Pearson, p 6770. s.f.

12. Bello L. A. et al. Propiedades químicas y funcionales del almidón modificado de plátano Musa paradisiaca L. (Var. Macho). Agrociencia, p 169-180. 2002.

13. Benavides, H. Guía de aplicación de técnicas de microbiología (bacterias y hongos) para ser utilizado en microbiología general. San Salvador: Universidad de El Salvador. 2007.

14. Brabender ${ }^{\circledR} \mathrm{GmbH}$ \& Co. KG, Micro Visco-Amilógrafo ${ }^{\circledR}$. Ficha técnica de equipo. 2018.

Disponible

En: https://www.brabender.com/typo3conf/ext/cokcb2web/Resources/Public/Files/fi les.php?d=1\&p=WTJRMG1Zd01WbE9XNVptVVpqVTFqZ3dOUmxZVGIPR1p OR1k9X1laRXpaMmhp.pdf

15. Caicedo Dia, G. E., Rozo Wilches, L. S., Rengifo Benitez, G. La achira alternativa agroindustrial para áreas de economía campesina. CorpoicaPronatta, p 14-15. 2003.

16. Canales, P., Chavez, E. Caracterización de bacterias halófilas productoras de amilasas aisladas en las Salinas de San Blas. Revista colombiana de biotecnologia, p 150-157. 2014.

17. Casarrubias, $\mathrm{G}$ et al., Diferencias estructurales y reológicas entre almidones de frutas y cereales. Agrociencia, 46 (5). 2012.

18. Espinisa Solis, V. Yautepec: Instituto Politécnico Nacional. 2008.

19. Galvis, M. Estudio del proceso de fermentación de glucosa para la producción de bioetanol a partir de levaduras nativas. s.l.: Universidad Industrial de Santander. 2009.

20. Gonzales Góngora, I., Hernández Muños, D. Modificación del almidón de sagú por vía química, física y enzimática. Revista de Ciencias Farmacéuticas y Alimentarias, 1 (2). 2015.

21. Granados, C. et al. Propiedades funcionales del almidón de sagú (Maranta arundinacea). Biotecnología en el sector agropecuario y agroindustrial, p 90-96. 2014.

22. Hernandez, M., Torruco, J., Chel, L., Betancur, D. Caracterización fisicoquímica de almidones de tubérculos cultivados en Yucatán, México. Food Science and Technology, 28 (3): 718-726. 2008.

23. Hoyos Leyva, J. et al. Morphological, Physicochemical and functional characteristics of starch from Maranta ruiziana Koern. LWT- Food Science and Tecnology, p 150-156. 2017.

24. INTEK GROUP S.A.S, Inteckgroup. 2018. Disponible En: http://intekgroup.com.co/microscopia/microscopio-electronico-de-barrido/

25. ISI. Determination or starch size distribution by screening. s.I. 2015. Disponible En: http://www.starch.dk/isi/methods/index.htm

26. Manmeet, K., Oberio, D., Sogi, D., Gill, B., Physicochemical, morphological and pasting properties of acid treated starches from different botanical sources. Journar Food Sci Tecnhnol, 48 (4): 460-465. 2011. 
27. Martinez, F., López, M., Zazueta, J., Morales, E. Preparación y propiedades de almidones pregelatinizados de yuca (Manihot esculenta. Crantz.) y Jímica (Pachyrhizus erosus) usando calentamiento óhmico. Agrociencia, p 275-283. 2005.

28. Martïnez O. et al. Mecanismos de gelatinización del almidón nativo de banano exportable del Ecuador. Revista Colombiana de Química, 44 (2): 16-21. 2015.

29. Meaño Correa, N., Ciarfella Perez, A., Dorta Villagas, A. Caracterización morfológica y perfil viscoamilografico del almidón nativo de Ñame congo (Dioscorea bulbifera L.). Saber, Universidad de Oriente, p 250-256. 2016.

30. Mejía, A. Director de I+D de alimentos y productos en polvo POLTEC S.A.S. [Entrevista] Feb. 2019.

31. Meré, J. Madrid: Univesidad Carlos III de Madrid. 2009.

32. Miranda, J. A. Evaluación del efecto de Lactabacillus casei y de la mezcla de cepas (Delbruekii ssp. Bulgaricus, bifidobacterium) sobre dos propiedades funcionales del almidón agrio de yuca (Manihot sculenta crantz). Bogotá D.C.: Fundación Universitaria Agraria de Colombia. Facultad Ingeniería de Alimentos. 2014.

33. Miyasaki, M., Van Hung, P., Maeda, T., Morita, N. Avances recientes en la aplicación de almidones modificados para panificación. Tendencias en Ciencia y Tecnología de Alimentos, 17 (11): 591-599. 2006.

34. Murúa B, B., Martinez, F. Preparation of starch derivaties usong reactive extrusion and evaluation of modified starches as shell material for encapsularion of flavoring agents by spary drying. Journal of Food Enguneering, p 380-386. 2011.

35. Niño Lopez, A. M., Romero Garzon, A. M. Caracterización fisicoquímica del almidón de yuca fermentado variedad -brasilera- Mcol 2737 con proyección a aplicaciones agroindustriales. Villavicencio: Tesis de grado Universidad de los Llanos. 2016.

36. Ovelar V. Seminario gelatinización y retrogradación. 2019. Disponible En: https://www.studocu.com/en/document/universidad-nacional-de-la-

plata/estructural/summaries/seminario-gelatinizacionyretrogrdacion25483/1599438/view

37. Peñaranda C, O. I., Perilla, J. E., Algecira E., N. A. Revisión de la modificación química del almidón con ácidos orgánicos. Revista ingeniería e investigación, Diciembre, 28 (3): 47-52. 2008.

38. Ramírez, J. C. et al. Bacterias lácticas: importancia en alimentos y sus efectos en la salud. Revista Fuente, 2 (7). 2011

39. Rincón Suarez, L., Villamil Novoa, F. A. Obtención y caracterización fisicoquímica y microbiológica del almidón agrio para el mejoramiento del proceso de fermentación. Bucaramanga: Universidad Industrial de Santander. 2005.

40. Rodriguez Borray, G. A., Garcia Bernal, H. R., Camacho Tamayo, J. H., Arias G., F. L. El almidón de achira o Sagú (Canna edulis. Ker) manual técnico para su elaboración. En: Tibaitatá, Cundinamarca: Corpoica- Pronnatta. 2003.

41. Rodríguez, G., García, H., Camacho, J., Rivera, J. Concepción de un modelo de agroindustria rural para la elaboración de harina y almidón a partir de raíces y tubérculos promisorios, con énfasis en los casos de achira (Canna edulis), 
arracacha (Arracacia xanthorriza) y ñame (Dioscorea sp.), Tibaitatá: Corpoica \& Pronatta. 2003.

42. Smith, R. Characterization and analysis of starches. Caracterización y análisis de almidones. Stach: Chemistry and technology, Vol. II, p 593. 1967.

43. Terebiznik, M. R. Alfa-amilasa de Aspergillus oryzae: Estudios de producción por fermentación en sustrato sólido, purificación y estabilización. Buenos Aires: Biblioteca Digital FCEN - UBA. 1998.

44. Thitipraphunkul, K., Uttapap, D., Piyachamkwam, K., Takeda, Y. A comparative study of adible canna (Canna edulis) starch from different cultivars. Part I. Chemical composition and physicochemical properties. Carbohydrate Polymers, 53 (3): 317-324. 2003.

45. Vargas, G., Marínez, P., Velezmero, C. Propiedades funcionales de almidón de papa (Solanum tuberosum) y su modificación química por acetilación. Scientia Agropecuaria, 7 (3): 223-230. 2016.

46. Velíz, R. Hidrólisis del almidón de yuca por fermentación sumergida con Azpergillus Niger para la obtención de glucosa y producción de alcohol etílico. s.l.:s.n. 1984.

47. Villagra, A. Almidón retrogradado en el tratamiento dietoterápico de la Diabetes Mellitus tipo 2. Licenciatura en alimentación. Universidad ISALUD, 21 p. 2010. 